\title{
REVIEW OF DESIGN HEURISTICS AND DESIGN PRINCIPLES IN DESIGN FOR ADDITIVE MANUFACTURING
}

\author{
Valjak, Filip (1); \\ Lindwall., Angelica (2) \\ 1: University of Zagreb, FSB; \\ 2: Luleå University of Technology, Department of Business Administration, Technology and Social \\ Sciences
}

\begin{abstract}
The advent of additive manufacturing (AM) in recent years have had a significant impact on the design process. Because of new manufacturing technology, a new area of research emerged - Design for Additive Manufacturing (DfAM) with newly developed design support methods and tools. This paper looks into the current status of the field regarding the conceptual design of AM products, with the focus on how literature sources treat design heuristics and design principles in the context of DfAM. To answer the research question, a systematic literature review was conducted. The results are analysed, compared and discussed on three main points: the definition of the design heuristics and the design principles, level of support they provide, as well as where and how they are used inside the design process. The paper highlights the similarities and differences between design heuristics and design principles in the context of DfAM.
\end{abstract}

Keywords: Design for Additive Manufacturing (DfAM), Additive Manufacturing, Design methods

\section{Contact:}

Valjak, Filip

University of Zagreb, FSB

Department of Design

Croatia

fvaljak@fsb.hr

Cite this article: Valjak, F., Lindwall, A. (2021) 'Review of Design Heuristics and Design Principles in Design for Additive Manufacturing', in Proceedings of the International Conference on Engineering Design (ICED21), Gothenburg, Sweden, 16-20 August 2021. DOI:10.1017/pds.2021.518 


\section{INTRODUCTION}

In recent years, Additive Manufacturing (AM) and Design for Additive Manufacturing (DfAM) are gaining growing attention from both design researchers and design practitioners (Pradel et al., 2018a). The advent of AM and its immense application in different industries due to unique AM capabilities enhanced AM specific design knowledge's rapid growth. The main reasons for the specificity of AM design knowledge are the nature of AM technologies and the unique AM capabilities it offers, such as geometrical freedom, ability to shape material across product, or manufacturing of the fully functional product in a single build (Gibson et al., 2015; Thompson et al., 2016).

The DfAM knowledge, accumulated through design research and practice, is utilised through numerous forms. The most common forms inside DfAM are design heuristics, design principles, design guidelines, and design rules (Pradel et al., 2018b). The DfAM knowledge is then applied through different DfAM methods and tools across different stages of the design process, from ideation and conceptual design phase to detail design (Pradel et al., 2018b).

Nowadays, numerous DfAM approaches can be found in literature, and designers face a challenge about which one to use and where inside the design process to apply them to develop an AM product. As in the product design process designers have the biggest influence on the form and architecture of the product in the conceptual design phase (Pahl et al., 2007; Ulrich and Eppinger, 2007) to design genuine AM products and not just redesign existing ones to suit new manufacturing technology, the DfAM knowledge needs to be applied from the early design phases. From the previously mentioned DfAM design knowledge forms, the most suitable forms in the early design phases are design heuristics and design principles (Andreasen et al., 2015; Yilmaz et al., 2016).

This paper aims to explore how design heuristics and design principles in the context of DfAM can be involved in product design for AM. The presumption is that design heuristics and design principles for $\mathrm{AM}$, as two similar but different forms of design support, need to be treated differently in DfAM and early design phases. The study explores the current literature sources on design heuristics and design principles inside the DfAM. Therefore, the main research question of this paper is:

How does current literature treat design heuristics and design principles in the context of DfAM in relation to a new design of AM products?

To answer the stated research question, a systematic literature review was conducted to find all relevant papers on the topic of design heuristics and design principles in the context of DfAM and to differentiate the two terms based on the literature sources. The paper is structured as follows. Firstly, background literature on design heuristics and design principles in general design theory is presented in Section 2. The methodology and protocol of the systematic literature review are given in Section 3. Sections 4 and 5 present the results of the conducted search in the literature. Section 6 discusses and compares the results, while the conclusion of the paper is given in Section 7.

\section{BACKGROUND}

Design science is a developing research field (Papalambros, 2015), with a growing amount of design knowledge accumulated through design research. Seeing design science as a broad and interdisciplinary field, the knowledge gained through design research is often context dependent and is continuously evolving and needs to be captured and stored in a formal form. Over the years, many design knowledge formalisations were proposed. Nowadays, design knowledge is being formalised in numerous forms at various levels of specificity (Fu et al., 2016). The formalisations developed so far are focused on different phases of the design process and emerge under different terms in literature, such as principles, heuristics, guidelines, rules, strategic constructs, rules of thumb, etc. (Fu et al., 2016). For brevity, in this overview, only heuristics and principles are reviewed as the types of design support of interest in the conceptual design phase, and for a broader overview of knowledge formalisations, please refer to Fu et al. (2016).

Design heuristics are knowledge formalisation based on designers' experience and tacit knowledge. They are used in conceptual design when possible design solutions are abstract, and a designer needs to make choices (Chong et al., 2009). Gao et al. (2015) highlight the need to develop design heuristics specifically for different AM processes, to support the exploration of the new and large design space that AM can offer. According to Yilmaz and Seifert (2011), design heuristics do not assure the finding of a solution for a given design problem but rather provide a "quick and dirty" method that enables the search for an acceptable solution. Similarly, Stone et al. (2000) use heuristics in their method for 
establishing a product architecture as a set of steps designers use in the design process to identify modules in a given design problem.

The formal definition of the design heuristic used in this study is given by Fu et al. (2016):

"A context-dependent directive, based on intuition, tacit knowledge, or experiential understanding, which provides design process direction to increase the chance of reaching a satisfactory but not necessarily optimal solution."

On the other hand, design principles are usually based on both designers' experience and empirical evidence. According to McAdams (2003), design principles are valuable resources of knowledge that provide qualitative rather than quantitative information to the designer. They are rarely universal but somewhat context-dependent, often described as generalised directives (Singh et al., 2009) applicable in a given context. The principles can improve the design process and act as guidance for the designers to implement possible ideas and features into the concept of a product (Perez et al., 2011). Mattson and Wood (2014) define the design principles as a fundamental proposition for guidance throughout the design process that helps designers achieve an adequate solution. Pahl \& Beitz state that principles allow the solutions to emerge and see principles as a first step in the implementation of the solution in conceptual design (Pahl et al., 2007).

The formal definition of the design principle used in this study is given by Fu et al. (2016):

"A fundamental rule or law, derived inductively from extensive experience and/or empirical evidence, which provides design process guidance to increase the chance of reaching a successful solution."

\section{METHODOLOGY}

To review the design heuristics and the design principles in the context of DfAM, a systematic literature review was conducted. The protocol of the systematic literature review was established according to approaches from Kitchenham and Charters (2007), PRISMA statement (Liberati et al., 2009) and Fink (2014). The protocol for conducting the systematic literature review consisted of the following activities: the definition of review protocol, a gathering of relevant papers, and synthesis of the results. The search was conducted individually for both design heuristics and design principles. The flow diagram of conducted systematic literature is shown in Figure 1.
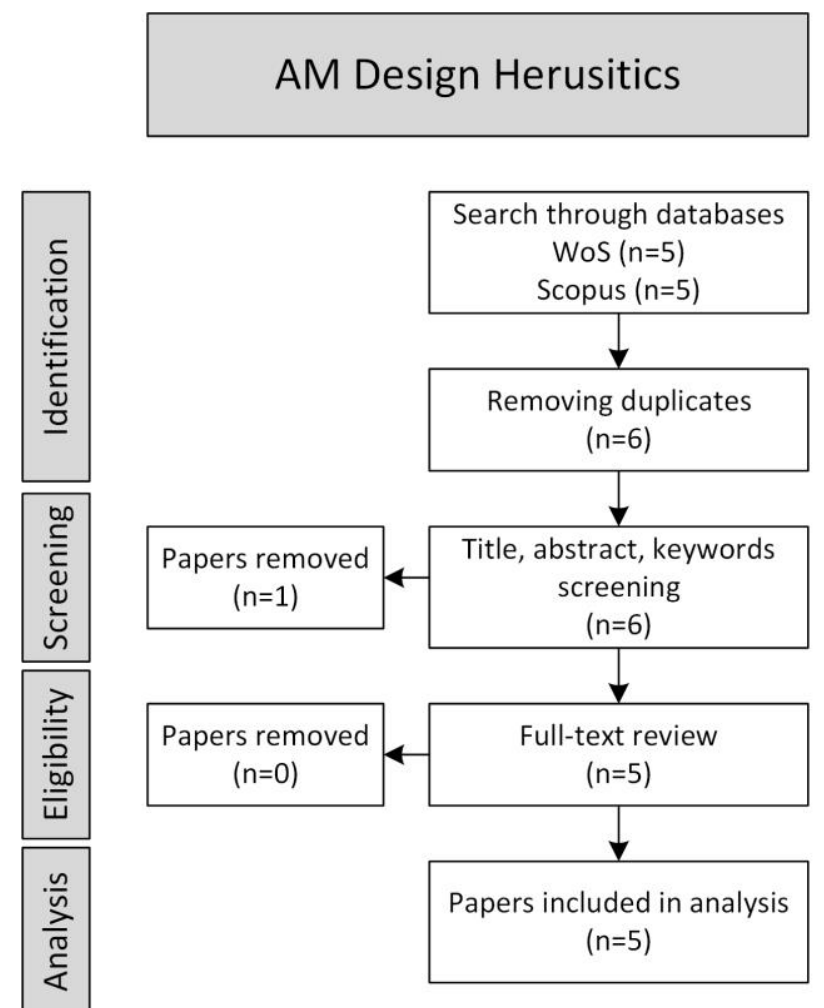

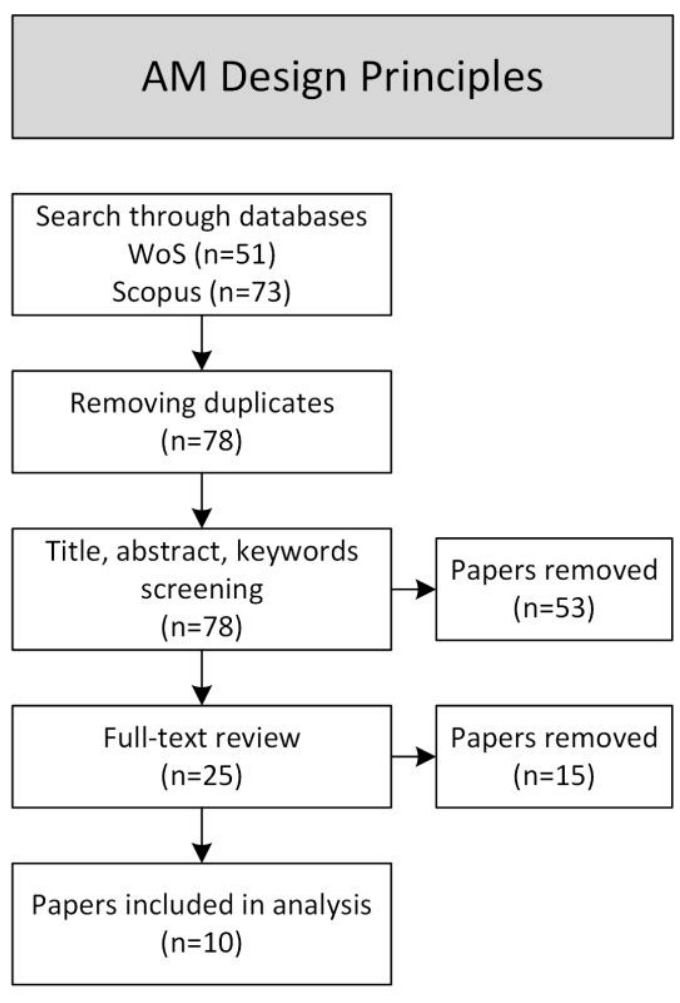

Figure 1. Flow diagram of conducted systematic literature review 
To conduct a search two strings of keywords with the Boolean operator and wild character for the inclusion of both singular and plural forms were used, ["design heuristic*" AND "additive manufacturing"] for searching of AM design heuristics, and ["design principle*" AND "additive manufacturing"] string for search on AM design principles. The search was conducted on titles, abstracts and keywords using web search engines of Web of Science and Scopus databases (Chadegani et al., 2013).

The keyword search in both databases revealed 10 papers on the design heuristics and 125 papers on the design principles in the context of AM and DfAM. To remove duplicates, titles and DOI numbers were compared, thus 6 and 78 papers remained. For each paper, title, abstract and keywords were checked, and the papers that didn't comply with the inclusion criteria were removed. The inclusion criteria were: (a) paper presents either design heuristics or design principles in the context of AM, (b) the design heuristics or design principles are applicable in the product design process inside the field of engineering design. The described process eliminated 1 paper on design heuristics and 53 papers on design principles. A total of 30 papers were left for full-text review that was conducted with the same inclusion criteria and with further consideration of scientific rigour. The full-text review removed additional 15 papers on design principles, thus for final comparison, 5 papers on design heuristics and 10 on design principles remained.

\section{DESIGN HEURISTICS FOR AM}

Design heuristics in the context of DfAM (DH) were initially explored and formulated by BlöschPaidosh \& Shea (2017), where a number of DH were derived from a pool of over 200 AM artefacts. They later tested these DH in an experiment with 29 participants (Blösch-Paidosh and Shea, 2018), mainly including novice designers (students). The experiment provided positive results, showing that novice designers gain support through the $\mathrm{DH}$, and ultimately produced better outcomes. Lindwall \& Törlind (2018) reduced the number of DH to test the usage at a one-day workshop with experienced designers. Similar to the previous study (Blösch-Paidosh and Shea, 2018), they concluded that DH supported designers in exploring the new design space. Blösch-Paidosh et al. (2019) continued their evaluations of $\mathrm{DH}$ with novice designers, also with positive outcomes on idea generation while redesigning for AM. The latest paper on DH for AM was published in 2019, where Blösch-Paidosh \& Shea (2019) designed cards for their heuristics. The cards aimed to convey relevant information to the designer and were tested on 27 novice designers. The experiment showed that designers who had access to cards produced a higher level of AM design modifications than designers who did not have DH cards. The Table 1. compare all studies found on DH in the context of AM regarding the definition of DH provided in the study, the number of DH given, and the design phase where the DH are indented to be applied.

Table 1. Overview of design heuristics in context of DfAM

\begin{tabular}{llcl}
\hline Author (Year) & Definition of DH & $\begin{array}{l}\text { Number } \\
\text { of DH }\end{array}$ & Design phase \\
\hline $\begin{array}{l}\text { Blösch-Paidosh } \\
\text { and Shea (2017) }\end{array}$ & $\begin{array}{l}\text { Used definition from Fu et al. (2016) } \\
\text { quoted above }\end{array}$ & $\begin{array}{l}\text { Early stages of the } \\
\text { product design process }\end{array}$ \\
\hline $\begin{array}{l}\text { Blösch-Paidosh } \\
\text { and Shea (2018) }\end{array}$ & $\begin{array}{l}\text { "designers need process- and material } \\
\text { independent methods, which offer high- } \\
\text { level inspiration in the early phases of } \\
\text { design." }\end{array}$ & $\begin{array}{l}\text { Early stages of the } \\
\text { product design process }\end{array}$ \\
\hline $\begin{array}{l}\text { Lindwall and } \\
\text { Törlind (2018) }\end{array}$ & $\begin{array}{l}\text { towards the exploration of design } \\
\text { variations" (from Daly et al., 2012) }\end{array}$ & 10 & $\begin{array}{l}\text { Creative phases of } \\
\text { product design process }\end{array}$ \\
\hline $\begin{array}{l}\text { Blösch-Paidosh } \\
\text { et al. (2019) }\end{array}$ & $\begin{array}{l}\text { design heuristics for AM is } \\
\text { demonstrated to promote AM design } \\
\text { freedom" }\end{array}$ & 29 & $\begin{array}{l}\text { Early phases of the } \\
\text { design process }\end{array}$ \\
\hline $\begin{array}{l}\text { Blösch-Paidosh } \\
\text { and Shea (2019) }\end{array}$ & $\begin{array}{l}\text { Used definition from Fu et al. (2016) } \\
\text { quoted above }\end{array}$ & 29 & $\begin{array}{l}\text { Early phases of the } \\
\text { product design process }\end{array}$ \\
\hline
\end{tabular}




\section{DESIGN PRINCIPLES FOR AM}

The first report of design principles in the context of DfAM (DP) found in literature dates from 2014. Rosen (2014) presented four high-level DP for DfAM derived from observations and examples of existing designs. These four DP are focused on (i) utilisation of complex geometry, (ii) customisation of geometry for individual users, (iii) direct manufacturing, and (iv) utilisation of multi-materials. Although the author does not explicitly specify the intention when to apply the DP, due to their broadness and abstraction, they are mostly suitable for early design phases. On the other hand, Perez et al. (2015) observed crowdsourced AM designs from which they extracted 23 unique AM DP categorised on three groups (quality, functionality, printability) based on the improvement attribute. The DP are goal-directed and are not mutually exclusive, thus conflicts of DP can occur when applied. Due to the source of designs from which they are extracted, these 23 DP are oriented on manufacturability and are to be used in the detail design and manufacturability of AM products (e.g. wall thickness, support structure, STL file, part orientation, etc.), thus are similar to the design guidelines and not fully suitable for early design stages. The DP are represented with one statement, followed by a short description and, in some cases, a figure.

The crowdsourced DP developed by Perez et al. were later expanded and reformulated to support innovation with AM during early design stages and are formalised in the form of 27 AM Principle Cards (Lauff et al., 2019; Perez, Hilburn, et al., 2019). Here the AM design knowledge is written with formal syntax and further described with schematics and examples. The DP are organised in four categories (product, business process, design process, printing) and are to be used in Design Innovation with AM Methodology (Perez, Lauff, et al., 2019). With this transformation, their applicability is expended to be used throughout the design process, but also can be used in the business assessment of AM product development. The cards were validated through an experimental procedure that included 85 participants from novices to professional designers. The results showed the usefulness of the cards in the given concept generation design task, as the majority of the participants stated their benefits.

Furthermore, Leutenecker-Twelsiek et al. (2016) refer to the DP as design support for transferring concept into a specific manufacturable design. Accordingly, the principle they presented ("Early Determination of Part Orientation") is focused on defining part orientation in the early embodiment of the concept. While Leutenecker-Twelsiek et al. are using AM DP to apply some of the manufacturing specificities of AM in transition between conceptual and embodiment design, Mani et al. (2017) define $\mathrm{DP}$ as an intermediator between general guidelines and prescriptive design rules. This view on DP is intended to be used in later design phases, as it formally encodes the design knowledge as a function between geometry related parameters and machine parameters, thus this concept of DP is intended to be used in later design phases when the layout of the product is known.

On the other hand, Valjak et al. (2018) see DP as high-level sources of design knowledge used to solve a particular function during the conceptualisation of a product. In the proposed framework of AM oriented design process, the DP are formal sources of DfAM design knowledge that can be mapped on product functions. Later, Valjak and Bojčetić (2019) adopted the definition of DP from Fu et al. (2016) and proposed a broader design repository of AM design principles. In the proposed repository, AM DP are stored and described through multiple elements of representation, from text descriptions and pictures to CAD and physical models, used for the transfer of AM knowledge to the designers. Along with the elements of representation, the DP are categorised according to the product function that they are solving. A similar systematisation of the design principles is used by Schumacher et al. (2019) who developed 23 DP based on a multi-material aspect of AM. The DP are systemised through the function-flow matrix, with three types of flows (material, energy and signal) and six general operations of functions (store, channel, change, convert, connect, branch). The DP are stored and represented through principle cards with a textual and graphic description of DP, but also contain remark regarding AM capabilities and limitations. The principle cards are intended to be used during conceptual design to support ideation and development of AM concepts. The Table 2. compare all studies found on DP in the context of DfAM regarding the definition of DP provided in the study, the number of DP given, and the design phase where the DP are indented to be applied. 
Table 2. Overview of design principles in context of DfAM

\begin{tabular}{llcl}
\hline Author (Year) & Definition of DP & $\begin{array}{l}\text { Number } \\
\text { of DP }\end{array}$ & Design phase \\
\hline Rosen (2014) & not provided & 4 & $\begin{array}{l}\text { Entire design process, } \\
\text { suitable for early design }\end{array}$ \\
\hline $\begin{array}{l}\text { Perez et al. } \\
(2015)\end{array}$ & $\begin{array}{l}\text { "design principle is an actionable } \\
\text { guideline that, given a certain design } \\
\text { goal, } \text { improves the likelihood of success" }\end{array}$ & 23 & $\begin{array}{l}\text { Suitable for detail design } \\
\text { and manufacturing } \\
\text { preparation }\end{array}$ \\
\hline $\begin{array}{l}\text { Leutenecker- } \\
\text { Twelsiek et al. } \\
(2016)\end{array}$ & $\begin{array}{l}\text { "Design principles support the designer } \\
\text { to transfer a principle solution into a } \\
\text { specific, manufacturable design" }\end{array}$ & 1 & $\begin{array}{l}\text { Entire design process, } \\
\text { suitable for early design }\end{array}$ \\
\hline $\begin{array}{l}\text { Mani et al. } \\
\text { (2017) }\end{array}$ & $\begin{array}{l}\text { logical correlations capturing process } \\
\text { parameter and control parameters } \\
\text { derived from DGs and corresponding } \\
\text { DFs" }\end{array}$ & $/$ & Suitable for detail design \\
\hline $\begin{array}{l}\text { Valjak et al. } \\
\text { (2018) }\end{array}$ & not provided & $/$ & $\begin{array}{l}\text { To be used in early } \\
\text { design phases }\end{array}$ \\
\hline $\begin{array}{l}\text { Perez, Hilburn, } \\
\text { et al., (2019) }\end{array}$ & $\begin{array}{l}\text { Used definition from Fu et al. (2016) } \\
\text { quoted above }\end{array}$ & 26 & $\begin{array}{l}\text { Entire design process, } \\
\text { suitable for early design }\end{array}$ \\
\hline $\begin{array}{l}\text { Lauff et al., } \\
\text { (2019) }\end{array}$ & Refer to Fu et al. (2016) & 27 & $\begin{array}{l}\text { Entire design process } \\
\text { and beyond, suitable for } \\
\text { early design }\end{array}$ \\
\hline $\begin{array}{l}\text { Perez, Lauff, et } \\
\text { al., (2019) }\end{array}$ & Refer to previous work & $\begin{array}{l}\text { Entire design process } \\
\text { and beyond, suitable for } \\
\text { early design }\end{array}$ \\
\hline $\begin{array}{l}\text { Valjak and } \\
\text { Bojčetić (2019) }\end{array}$ & $\begin{array}{l}\text { Used definition from Fu et al. (2016) } \\
\text { quoted above }\end{array}$ & $/$ & $\begin{array}{l}\text { To be used in early } \\
\text { design }\end{array}$ \\
\hline $\begin{array}{l}\text { Schumacher et } \\
\text { al. (2019) }\end{array}$ & Not provided & $\begin{array}{l}\text { To be used in early } \\
\text { design }\end{array}$ \\
\hline
\end{tabular}

\section{DISCUSSION}

The conducted systematic literature review revealed 15 papers on the topics of DH and DP in the context of DfAM, with $1 / 3$ being about DH and 2/3 on DP. To answer the stated research question, how does current literature treat DH and DP in the context of DfAM, the results are analysed, compared and discussed on three main points: the definition of the DH and DP, level of support provided by DH and DP, as well as where and how are DH and DP used inside the design process.

From the results of the literature review, the consistency of the terminology can be observed. While the term design heuristics is unambiguously used to define the design support for ideation in the context of DfAM, the term design principles is used inconsistently to define different design supports at a different level of support across the design process, from early design to detail design and manufacturing preparation. The common understanding of the DH in the context of DfAM sees the $\mathrm{DH}$ as design support for the early phases of the design process. The DH are context-dependent and are based on tacit knowledge (Fu et al., 2016). On the other hand, the definitions of DP vary among the reviewed papers. Some authors provide their own definition, while others adopt the definition of DP provided by Fu et al. (2016). Most definitions of DP look on DP as design support based on the empirical evidence used for concept generation and embodiment of particular AM solutions, but some (e.g. Mani et al. (2017)) look on the DP as a link between the complete design and manufacturing parameters.

The DH in the context of DfAM are a high-level type of design support, that steer designers to explore the possibilities of AM, without specifying the ways how particular form and function can be achieved. For example, the AM heuristic \#9 (Blösch-Paidosh and Shea, 2017) "Convey information with geometry" suggest that information can be embedded in the geometry of the product, but do not 
provide additional context or information on how to embody the particular DH into a product. On the other hand, the majority of reviewed papers look on the DP in the context of DfAM as a medium-level to high-level design support. The example of DH given above transformed into a DP could be "Convey information with geometry by recessing the product surface". Such syntax of the DP provides the designer with additional information on how to achieve a particular form or functions needed for detail concept design and their embodiment. However, if the DP is looked as a link with the manufacturing parameters (a lower-level type of design support), then they should contain additional numerical data specifying the parameters for successful manufacturing needed in detail design (e.g. "Convey information with geometry by recessing the product surface by $0.4 \mathrm{~mm}$ for manufacturing with XY AM process/machine").

Based on the definitions and the level of support the DH and DP provide, their utilisation throughout the design process according to Ulrich et al. (2007) can be observed. The DH are mainly intended to be used in concept development (Figure 2.) The aim of the DH is to help designers to perceive the unique capabilities of $\mathrm{AM}$ and to be a source of inspiration for creative activities during concept generation. Furthermore, DH support exploration of design space enabled with AM to fully take advantage of the possibilities that AM can offer. On the other hand, utilisation of DP is spread-out across the design process (Figure 2.) Depending on the embodiment of the DP, they can be used from concept generation and embodiment design, all the way to the detail design. Nevertheless, most of the research on DP in the context of DfAM look on the DP as support for concept generation and their embodiment, thus their main purpose is to support the early design and its realisation in a form suitable for AM. The application of DH and DP during the design activities is not strictly separated, and their usage overlaps on the transition from concept development to system level design stage (Figure 2.) While the DH are mainly used for exploration of the AM design space, the DP are mostly used for narrowing the design space towards a particular AM based solution. There is no exact dividing line between the two, but rather the blurry area when both can be applied. Both DH and DP support designers in gaining new knowledge and understanding regarding AM in design. Their application in the product design process depends on the designer's familiarity with both supports, particular design problem and context of the design process.

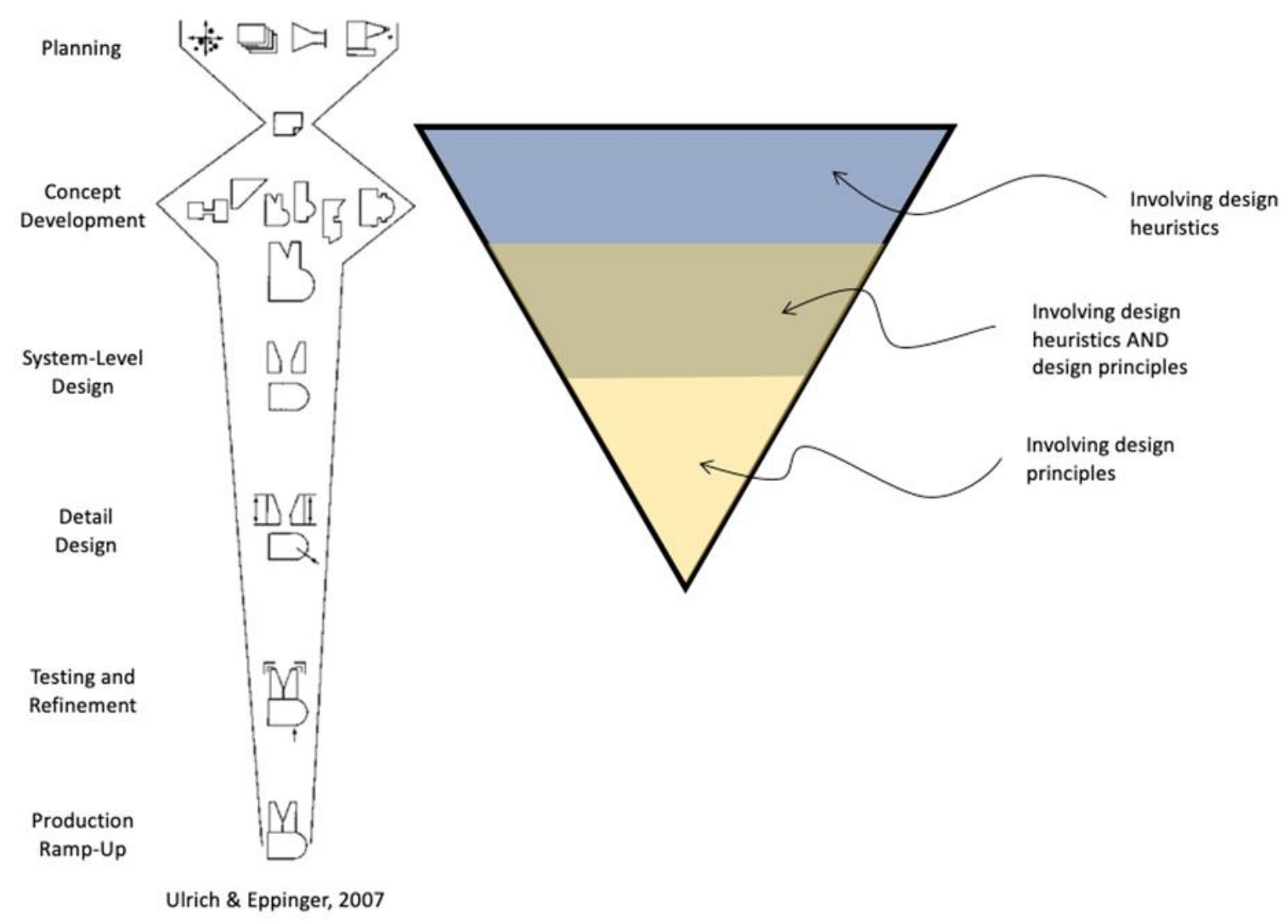

Figure 2. Design heuristics and design principles for am related to the product design process (adopted from Ulrich \& Eppinger, 2007) 
Since DH and DP are not used in the same context and design stage, their linkage with particular AM technology is different. DH are process and material independent (Blösch-Paidosh and Shea, 2017); thus, by using DH designer is not oriented on any AM technology and uses DH to explore AM enabled design space. Therefore, the concept of the product developed with DH could be unfeasible with the current state of the technology and would require additional redesign. On the other hand, DP are more dependent on the process and material and could relate to a particular AM technology. Nevertheless, some authors are proposing the development of broader DP that are related to multiple AM technologies (e.g. Valjak and Bojčetić (2019)) while other developed DP for particular AM technology (e.g. Perez et al. (2015)). Hence, when DP are used in conceptual design, the concept of the product is usually feasible as it incorporates some limitations of AM. Furthermore, when a designer knows that she/he is working with a particular AM technology, DP could be a better choice as a support for the design process as it limits design space on what is feasible.

The final remark on the existing DH and DP in the context of DfAM found in literature is on their validation. A majority of $\mathrm{DH}$ approaches found in the literature are validated through user studies with students (Blösch-Paidosh and Shea, 2018, 2019) and one study only involved professional designers (Lindwall and Törlind, 2018). On the other hand, only some DP are validated either through examples of how to apply design support method (Valjak et al., 2018) or user studies with students (Perez, Hilburn, et al., 2019) and none with the study inside the industrial setting. Studies on both DH and DP indicate benefits for supporting novice designers in adopting AM in design. However, there is not enough data to show the same support in an industrial setting. Designers working in an industrial setting have a great variety of requirements that need to be considered (such as material properties, AM process parameters, design qualification etc.), which makes adopting AM in design more complex than the inspirational and exploratory shape that DH and DP bring. Further studies with professional and experienced designers are needed to validate DH and DP usefulness in industrial applications.

\section{CONCLUSION}

In this work, a literature review on design heuristics and design principles in the context of the DfAM was conducted. The results showed the current status of research on both DH and DP and gave an overview of the current understanding of both terms. Furthermore, the paper emphasised the similarities and differences between DH and DP, as well as their aim, purpose and application inside the design process. Further research on DH and DP is suggested. It is important to acknowledge that this study only included two types of design supports. Therefore, additional reviews of other types of design supports (e.g. design guidelines, resign rules) in the context of DfAM are needed to organise and structure current literature findings, in order to aid future research and application of DfAM design support tools.

\section{ACKNOWLEDGMENT}

The authors acknowledge the financial support from LTU Graduate School of Space Technology and the EU project RIT (Space for Innovation and Growth).

\section{REFERENCES}

Andreasen, M.M., Hansen, C.T. and Cash, P. (2015), Conceptual Design, Springer International Publishing, Cham, https://doi.org/10.1007/978-3-319-19839-2.

Blösch-Paidosh, A., Ahmed-Kristensen, S. and Shea, K. (2019), "Evaluating the Potential of Design for Additive Manufacturing Heuristic Cards to Stimulate Novel Product Redesigns ”, Volume 2A: 45th Design Automation Conference, American Society of Mechanical Engineers, https://doi.org/10.1115/DETC2019-97865.

Blösch-Paidosh, A. and Shea, K. (2017), "Design heuristics for additive manufacturing”, in Maier, A., Škec, S., Kim, H., Kokkolaras, M., Oehmen, J., Fadel, G., Salustri, F., et al. (Eds.), DS 87-5 Proceedings of the 21st International Conference on Engineering Design (ICED 17) Vol 5: Design for X, Design to X, Vancouver, Canada, 21-25.08.2017, The Design Society, Vancuver, Canada, pp. 091-100.

Blösch-Paidosh, A. and Shea, K. (2018), "Preliminary User Study on Design Heuristics for Additive Manufacturing", Volume 2A: 44th Design Automation Conference, American Society of Mechanical Engineers, p. V02AT03A038; 10 pages.

Blösch-Paidosh, A. and Shea, K. (2019), "Design Heuristics for Additive Manufacturing Validated Through a User Study”, Journal of Mechanical Design, Vol. 141 No. 4, p. 041101. 
Chadegani, A.A., Salehi, H., Yunus, M.M., Farhadi, H., Fooladi, M., Farhadi, M. and Ebrahim, N.A. (2013), “A Comparison between Two Main Academic Literature Collections: Web of Science and Scopus Databases", Asian Social Science, Vol. 9 No. 5, https://doi.org/10.5539/ass.v9n5p18.

Chong, Y.T., Chen, C.-H. and Leong, K.F. (2009), “A heuristic-based approach to conceptual design”, Research in Engineering Design, Vol. 20 No. 2, pp. 97-116.

Fink, A. (2014), Conducting Research Literature Reviews: From the Internet to Paper, Fourth Edi., SAGE Publications, Inc., Los Angeles.

Fu, K.K., Yang, M.C. and Wood, K.L. (2016), "Design Principles: Literature Review, Analysis, and Future Directions”, Journal of Mechanical Design, Vol. 138 No. 10, https://doi.org/10.1115/1.4034105.

Gao, W., Zhang, Y., Ramanujan, D., Ramani, K., Chen, Y., Williams, C.B., Wang, C.C.L., et al. (2015), "The status, challenges, and future of additive manufacturing in engineering", Computer-Aided Design, Vol. 69, pp. 65-89.

Gibson, I., Rosen, D. and Stucker, B. (2015), Additive Manufacturing Technologies, Springer New York, New York, NY, https://doi.org/10.1007/978-1-4939-2113-3.

Kitchenham, B. and Charters, S. (2007), Guidelines for Performing Systematic Literature Reviews in Software Engineering, Technical Report, Version 2.3 EBSE Technical Report. EBSE 2007-1, Vol. 45, https://doi.org/10.1145/1134285.1134500.

Lauff, C.A., Perez, K.B., Camburn, B.A. and Wood, K.L. (2019), "Design Principle Cards: Toolset to Support Innovations With Additive Manufacturing", Volume 4: 24th Design for Manufacturing and the Life Cycle Conference; 13th International Conference on Micro- and Nanosystems, American Society of Mechanical Engineers, https://doi.org/10.1115/DETC2019-97231.

Leutenecker-Twelsiek, B., Klahn, C. and Meboldt, M. (2016), "Considering Part Orientation in Design for Additive Manufacturing", Procedia CIRP, Vol. 50, pp. 408-413.

Liberati, A., Altman, D.G., Tetzlaff, J., Mulrow, C., Gøtzsche, P.C., Ioannidis, J.P.A., Clarke, M., et al. (2009), "The PRISMA Statement for Reporting Systematic Reviews and Meta-Analyses of Studies That Evaluate Health Care Interventions: Explanation and Elaboration", PLoS Medicine, Vol. 6 No. 7, p. e1000100.

Lindwall, A. and Törlind, P. (2018), "Evaluating design heuristics for additive manufacturing as an explorative workshop method”, in Marjanović, D., Štorga, M., Škec, S., Bojčetić, N. and Pavković, N. (Eds.), DS 92: Proceedings of the DESIGN 2018 15th International Design Conference, The Design Society, Dubrovnik, Croatia, pp. 1221-1232.

Mani, M., Witherell, P. and Jee, H. (2017), "Design Rules for Additive Manufacturing: A Categorization", Volume 1: 37th Computers and Information in Engineering Conference, American Society of Mechanical Engineers, https://doi.org/10.1115/DETC2017-68446.

Mattson, C.A. and Wood, A.E. (2014), "Nine Principles for Design for the Developing World as Derived From the Engineering Literature", Journal of Mechanical Design, Vol. 136 No. 12, https://doi.org/10.1115/1.4027984.

McAdams, D.A. (2003), "Identification and codification of principles for functional tolerance design", Journal of Engineering Design, Vol. 14 No. 3, pp. 355-375.

Pahl, G., Beitz, W., Feldhusen, J. and Grote, K.-H. (2007), Engineering Design, Springer London, London, https://doi.org/10.1007/978-1-84628-319-2.

Papalambros, P.Y. (2015), "Design Science: Why, What and How”, Design Science, Vol. 1, p. e1.

Perez, A., Linsey, J., Tsenn, J. and Glier, M. (2011), "Identifying Product Scaling Principles: A Step Towards Enhancing Biomimetic Design”, Volume 2: Biomedical and Biotechnology Engineering; Nanoengineering for Medicine and Biology, ASMEDC, pp. 789-798.

Perez, B., Hilburn, S., Jensen, D. and Wood, K.L. (2019), "Design principle-based stimuli for improving creativity during ideation", Proceedings of the Institution of Mechanical Engineers, Part C: Journal of Mechanical Engineering Science, Vol. 233 No. 2, pp. 493-503.

Perez, K.B., Anderson, D.S., Hölttä-Otto, K. and Wood, K.L. (2015), “Crowdsourced design principles for leveraging the capabilities of additive manufacturing", Proceedings of the 20th International Conference on Engineering Design (ICED15), The Design Society, Milan, Italy, pp. 1-10.

Perez, K.B., Lauff, C.A., Camburn, B.A. and Wood, K.L. (2019), "Design Innovation With Additive Manufacturing: A Methodology", Volume 7: 31st International Conference on Design Theory and Methodology, American Society of Mechanical Engineers, https://doi.org/10.1115/DETC2019-97400.

Pradel, P., Zhu, Z., Bibb, R. and Moultrie, J. (2018a), "Investigation of design for additive manufacturing in professional design practice”, Journal of Engineering Design, Vol. 29 No. 4-5, pp. 165-200.

Pradel, P., Zhu, Z., Bibb, R. and Moultrie, J. (2018b), "A framework for mapping design for additive manufacturing knowledge for industrial and product design", Journal of Engineering Design, Vol. 29 No. 6 , pp. 291-326.

Rosen, D.W. (2014), "Research supporting principles for design for additive manufacturing", Virtual and Physical Prototyping, Vol. 9 No. 4, pp. 225-232. 
Schumacher, F., Watschke, H., Kuschmitz, S. and Vietor, T. (2019), “Goal Oriented Provision of Design Principles for Additive Manufacturing to Support Conceptual Design”, Proceedings of the Design Society: International Conference on Engineering Design, Vol. 1 No. 1, pp. 749-758.

Singh, V., Skiles, S.M., Krager, J.E., Wood, K.L., Jensen, D. and Sierakowski, R. (2009), "Innovations in Design Through Transformation: A Fundamental Study of Transformation Principles", Journal of Mechanical Design, Vol. 131 No. 8, https://doi.org/10.1115/1.3125205.

Stone, R.B., Wood, K.L. and Crawford, R.H. (2000), “A heuristic method for identifying modules for product architectures”, Design Studies, Vol. 21 No. 1, pp. 5-31.

Thompson, M.K., Moroni, G., Vaneker, T., Fadel, G., Campbell, R.I., Gibson, I., Bernard, A., et al. (2016), "Design for Additive Manufacturing: Trends, opportunities, considerations, and constraints", CIRP Annals, Vol. 65 No. 2, pp. 737-760.

Ulrich, K. and Eppinger, S. (2007), Product Design and Development, 4th Editio., McGraw-Hill Education, New York.

Valjak, F. and Bojčetić, N. (2019), "Conception of Design Principles for Additive Manufacturing", Proceedings of the Design Society: International Conference on Engineering Design, Vol. 1 No. 1, pp. 689-698.

Valjak, F., Bojčetić, N. and Lukić, M. (2018), "Design for Additive Manufacturing: Mapping of product functions", in Marjanović, D., Štorga, M., Škec, S., Bojčetić, N. and Pavković, N. (Eds.), DS 92: Proceedings of the DESIGN 2018 15th International Design Conference, The Design Society, Dubrovnik, Croatia, pp. 1369-1380.

Yilmaz, S., Seifert, C., Daly, S.R. and Gonzalez, R. (2016), “Design Heuristics in Innovative Products”, Journal of Mechanical Design, Vol. 138 No. 7, https://doi.org/10.1115/1.4032219.

Yilmaz, S. and Seifert, C.M. (2011), "Creativity through design heuristics: A case study of expert product design”, Design Studies, Vol. 32 No. 4, pp. 384-415. 